\title{
Forming the Basic Mathematical Knowledge among Technical Students
}

\author{
https://doi.org/10.3991/ijet.v15i03.11686 \\ Natalya Pugacheva $(\bowtie)$ \\ Kazan State University of Architecture and Engineering, Kazan, Russia \\ nata.pugacheva. 80 einbox.ru \\ Tatyana Kirillova \\ Research Institute of the Federal Penitentiary Service of Russia, Moscow, Russia \\ Olga Kirillova \\ Chuvash State University named after Ulyanov, Cheboksary, Russia \\ Aleksandr Lunev \\ Kazan National Research Technical University named after A.N. Tupolev-KAI, \\ Kazan, Russia \\ Oksana Pavlova \\ Kostroma State University, Kostroma, Russia
}

\begin{abstract}
Mathematical knowledge plays a system-forming role in education. The aim of this paper is to find out the didactic features of mathematical knowledge formation. The study involved 50 professors, 300 students. The criteria of mathematical knowledge acquisition include reliability, autonomy, and stability. The main study objectives are as follows. First, to clarify and scientifically substantiate special functions of mathematical knowledge in the process of engineering activity (bijection, formalization, relativity, and robustness). Second, to determine the formation of academic and applied mathematical knowledge. Technical knowledge can be applied using the special functions of mathematical knowledge. For example, in the form of mathematical models, or in a stable mathematical component in the professional outlook. The academic mathematical knowledge is focused on the systematic integrity of purpose, content, forms, methods and means of education. Along with transdisciplinary holistic worldview formation. Applied mathematical knowledge is focused on integration of teaching, educating, developing functions of education to acquire common cultural and professional competences. In modern conditions of rapid computerization, the opportunities to use mathematical analysis and modeling are increasing. However, basic mathematical knowledge is needed to assess the reliability of computer solutions.
\end{abstract}

Keywords - Mathematical knowledge, mathematics, mathematical literacy, mathematical outlook, mathematical education, transdisciplinary competence. 


\section{Introduction}

Mathematical knowledge does not have national boundaries. Mathematics is a global science. Mathematics, more than other subjects, has the ability to teach logic (develop the skills of reasoning, the ability to set the logical consequences from the initially given conditions, the ability to abstract and analyze, summarize, allocate the necessary and sufficient conditions to determine concepts, make judgments, finding ways to solve the problem) [1]. Mathematics creates transdisciplinary competence [2]. In October 1998, an international conference on Higher Education was hosted in Paris at UNESCO Headquarters [3]. The results of the conference were enshrined in the text of the "World Declaration on Higher Education for the Twenty-First Century: Vision and Action". The Declaration points to the need for a broad application of a transdisciplinary approach in solving complex socio-economic problems of society, organization and conduct of scientific research. The Declaration focuses on the formation of students' transdisciplinary competencies, including the ability to interpret disciplinary knowledge through the prism of universal (transdisciplinary) patterns and models of reality. Along with reduction skills, gaining experience in the use of transdisciplinary approach to solve complex multifactorial problems in the professional sphere. The advancement of knowledge through research is essential for all systems of higher education, which should promote postgraduate studies. Programs with long-term orientations on social and cultural aims and needs should promote and reinforce innovation, interdisciplinarity and transdisciplinarity. An appropriate balance should be established between basic and target-oriented research. Higher education institutions should educate students to become well informed and deeply motivated citizens, who can think critically, analyze problems of society, look for solutions to the problems of society, apply them and accept social responsibilities. The recommendations contained in this Declaration, received the support of higher education organizers in many countries around the world. In Russia, the declaration was included in the list of documents of expert-analytical and legal support for modernization of vocational training, quality management and accessibility of educational services [4]. In China, the provisions of the declaration were used in State Program on science and technology development "973" [5]. In the US, Declaration provisions were implemented in 2013 in the preparation of the Report "ARISE 2" (Advancing Research in Science and Engineering) [6]. In the report, the "locomotive" of American science and technology advanced development is discussed: the transition from interdisciplinarity to transdisciplinarity; development of cooperation and strengthening of synergy between science, government and private business.

The educational policy of Russian government is to improve mathematics education of citizens and mathematization of scientific knowledge. This policy is represented in the concept of mathematical education development, which was approved by the Decree of the Government dated $24^{\text {th }}$ Dec 2013 number 2506-P [7]. In the first section, the concept specifies that mathematics is a part of the world's scientific and technological progress [8]. The study of mathematics carries a backbone role in education, developing logical thinking person. Quality mathematics education is necessary for each person for a successful life in modern society. According to a concept of economic development, 
the country's success in the XXI century, and the creation of modern technologies depend on the level of mathematical science, education and literacy of the population. The accelerated development of mathematical education and science, providing a breakthrough in such key areas as information technology, engineering modeling, forecasting of natural and man-made disasters, would enhance Russia's prestige in the world. The following tasks were included in the concept of mathematical education development: curriculum modernization at all levels; rejection of the statement "incapable of mathematics"; ensuring access to the necessary information resources; improving the qualification of mathematics professors; support of mathematics education leaders. Professors of technical universities' mathematical departments, specified in the concept, should conduct research in fundamental mathematics and applied specialized fields, attracting students. In the context of enterprises modernization, their engineering support depends on a variety of parametric indices (labor input, cost, profit). Compliance of mathematical knowledge to the means and methods of technological industries ensures optimization of technical and economic parameters of a particular process [9]. This leads to the inclusion in the process of mathematical knowledge formation some educational material about optimizing process parameters in industries. It has been established that the effectiveness of bijection function increases with the inclusion of discipline "Mathematical methods in engineering technology". This discipline contributes to the formulation of mathematical knowledge and development of students' mathematical abilities, formation of readiness for minimizing costs, labor costs and maximizing productivity and profits in the engineering industries. This discipline also contributes to the development of industry problem-solving skills in students. Students will also be able to make choice based on optimal variants analysis, forecast the decision effects, and create engineering projects with a view on design, operational, economic parameters. The choice of solutions and the effectiveness of project activities are influenced by professional knowledge and experience, the ability to cooperate, to analyze socially significant problems and processes. Along with a willingness to maintain partnerships, the application of the basic methods for protecting industrial workers and the public from the consequences of man-made accidents, and natural disasters.

Lectures, practical and laboratory classes with analysis of specific work situations can be used to ensure the interconnection of cultural and professional competences in the process of mathematical knowledge formation. During lectures professor offers students to analyze the situation and to search for problem solutions. Consistently, production situations are simulated by formulating problem issues or problem posing tasks. This requires active cognitive activity and awareness of engineering social importance for the proper assessment and resolution. Problematic issue requires an unusual response. In the experience of students, there is no ready scheme for solving this question and discussing is needed. On the practical and laboratory studies, exploring the specific work situations, the students acquire the ability to analyze, to assess the situation and to make a decision. In these classes, students work in small groups, collectively discussing the results, proving the point of view and forming conclusions. Students learn to prove and argue. In the mathematical community the following ethical criteria is accepted: 
- The mathematician should be engaged in the matters, which allow precise formulation

- He/she confirms only that thing which has complete proof

- He/she cannot conceal the discovery of the evidence

- $\mathrm{He} / \mathrm{she}$ is obliged to present the discovery to the widest possible discussion, i.e. all interested persons should check it.

Teaching students by the methods and ethics of evidence - one of the components of mathematical knowledge formation process. The actualization of relativity function increases in the case of inclusion of the history of mathematics. The study of the historical and mathematical material optimizes:

- Acquisition of knowledge about the nature of mathematics as a component of human culture; mathematical perception of the world (n-dimensional space, measurement scales formalization et al.).

- Formation of mathematical proof as reliable and valid criteria of knowledge.

- General cultural and intellectual development; creating a positive image of mathematics as a universal scientific knowledge; understanding of mathematical aesthetics (beauty of geometrical figures, formulas, models); education of personal qualities (honesty, diligence, independence, criticality).

The training module "Mathematics and Mathematicians" was developed and implemented in educational practice to summarize the specifics of mathematical knowledge and present its development prospects, to study great scientists, whose names were given to mathematical theories, theorems, criteria, formulas, methods and other mathematical concepts. After completing this module, students will be able to work with catalogs, archives, information reviews, to make notes, summaries, and case statements, to perform publicly with scientific reports, to prepare scientific articles. Students grasp the "purity" of mathematical forms and relations, which, as in no other science, entails a particular importance of logic inferences. Robustness function provides mathematical component resistance in the professional worldview in conditions of destabilizing factors. The concept of "robustness" (from the English robust - strong, coarse) is used when the statistical procedures should "withstand" errors that can enter in the raw data or distort the conditions of probabilistic and statistical models used. In teaching, the concept of "robustness" is used to describe the state of the technology and the processes in which they are insensitive to the effects of destabilizing factors. The authors of this research have used this concept, based on the understanding the worldview as a systemic integrity of the content and the method of studying the world. Professional outlook is a developing subjective reality that determines the intellectual and value relation of the individual to the professional activity, the mechanism of self-development and enhancement of skills and knowledge. Mathematical component of professional outlook reflects the skills of logical reasoning and heuristic thinking.

Special functions of mathematical knowledge are important for engineer students. Didactic features of mathematical knowledge formation are driven by labor market needs, modernization of vocational training, new teaching technologies and the im- 
provement of teaching methodology. The purpose of the article is to find out the didactic features of mathematical knowledge formation among undergraduate technical students in Russian universities.

\section{Methodology}

The transdisciplinary approach is the methodological basis of the study. This approach provides for technology transfer skills formation from different scientific fields, readiness to solve complex multifactorial problems in the professional sphere. To implement this idea, the authors of this research referred to the binary principles of fundamentalization and professionalization. Fundamentalization principle provides the selection and structuring of the invariant mathematical knowledge, formation of students' skills of technology transfer from different scientific fields and readiness for continuous education throughout their lives. In the process of mathematical knowledge formation, fundamentalization principle is applied by means of rules set. Rules for the implementation of any principle reveal its practical focus, specific instructions. Rules for the implementation of fundamentalization principle include, firstly, the mathematization of knowledge, by means of a numerical expression of reality and revealing its quantitative limits, acquiring of mathematical proof techniques and mathematical modeling. If the university intends to give the student the concept of intuitive reasoning and logical reasoning, it should provide a place for geometric proof. Regardless of the type of language that is used to build the model, the basic logic of the study is the same in all cases.

The second rule of the principle of fundamentalization is to build an integrative module for solving the problems of common cultural and professional competences formation. The Charter of the Russian public organization "Association for Engineering Education of Russia" emphasizes that engineering education is of national strategic interests. Among the objectives of the organization are:

- Promotion of the improvement of engineering education content

- Ensuring fundamentalization, professionalization of the education content

- Formation of a high level of engineers' information culture

- Development of foreign language courses as a means of intercultural communication and academic mobility of students to improve the quality of engineering education

In the process of mathematical knowledge formation, professionalization principle is applied by means of rules set. The first rule - is to use the effect of the uncompleted task (the Zeigarnik effect). The latter is described as an artificial termination of learning process with the aim to find a solution and to create a students' motivation to study. Uncompleted task implies the subjective attitude of engineer students to problem solving. Such attitude might develop naturally, or under the influence of external circumstances. There are following types of uncompleted tasks:

- The problem with uncompleted condition (abnormal task), which facilitates the need to acquire sources of the missing condition. 
- Uncompleted action tasks, which fix in the memory the most important knowledge on the mathematization of technological processes.

- Tasks with the programmed error contributing to the development of generalization, abstraction, analytical skills.

- Tasks with redundant data that require data selection skills necessary for the mathematical models construction.

All kinds of uncompleted tasks allow obtaining the cumulative effect of teaching. Such effect is manifested in the students' stimulation to study, the development of abilities to generalization, abstraction, analysis, perception of information, setting goals and choosing the ways of achieving them. All of the latter are necessary for the construction of mathematical models.

The second rule of professionalization principle mathematical knowledge system quantization that enables the compression of educational information based on generalizations and creation of aggregative didactic units - taxons. Taxon - a group of objects having common features. All human activity depends on motives to solve personally significant problems. This allows allocating in activity the system quanta. It is known that any system of interacting particles is capable to form a stable state at certain values, it is all about the quantization principle. Quantization allows dividing the range of values for a certain number. In pedagogy, there is an idea of system quantization, which "leans" on the modular organization of the human cerebral cortex and is the basis of human mental activity functional systems, which are reflected in different sign systems (language, symbolic, graphic, etc.). All types of mathematical knowledge representations in a compressed compact form correspond to human property to think in images. When studying, absorbing, and pondering new knowledge, the encoding of such knowledge occurs; some schemes are drawn up in the mind. Compression of mathematical knowledge by means of four codes (symbolic, verbal, graphic and numeric) allows representing knowledge in the form of taxon. All representations of mathematical knowledge in a compressed compact form correspond to human property to think in images.

Taxons of mathematical knowledge are the subordinated quantity of knowledge and skills that are used in the learning process, linked by a certain degree of common features, properties and necessary for the formation of general cultural and professional competences. For each training topic taxon system is developed, which means some content in an electronic folder. The electronic folder includes a taxon of invariant knowledge; taxon practice-oriented knowledge; taxon, comprising interdisciplinary information; taxon, which includes a set of tasks for laboratory and practical classes; taxon, comprising the tasks for independent operation; taxon containing the properly executed samples on the learning theme. System quantization of mathematical knowledge allows forming knowledge in taxons and provides:

- The relationship of the invariant and practice-oriented mathematical knowledge and skills; systematization of industry objects and processes and its reflection by functional formulas. 
- The adaptation of computer system to the learning process; the formation of ability to understand the nature and significance of information in the development of machine-building production, to comply with the basic requirements of information security, to apply mathematical techniques and software tools in the process of engineering problems solving.

- Realization of interdisciplinary training of future engineers for creative wide-professional activity; functional and network representation of education content that makes it available for any subject.

The principles of fundamentalization and professionalization are dialectically interrelated and provide training for future engineers to solve a new type of cognitive and practical problems of professional activity.

Experimental work on the verification of didactic features effectiveness for mathematical knowledge formation took place in three phases (stating, forming, controlling). There were 350 people in the experiment: 50 professors, 300 students FSBEI HE "KNRTU-KAI" (Federal State Budgetary Educational Institution of Higher Education "Kazan National Research Technical University named after A.N. Tupolev-KAI"). Probabilistic sample of professors, students were drawn. The sample included faculty professors (average age 51) and associates (average age is 36 years) who conduct educational classes in mathematics with students enrolled in major "Design and technological support of machine-building industries". The sample included students of 3-4 courses enrolled in the mentioned major. None of the professors, the students refused to participate in the experimental work. With the help of a questionnaire, the attitude of professors and students was determined for the development of mathematical knowledge, and lessons criteria were identified. Closed-ended and open-ended questions were included.

Professors' questionnaire included the following closed-ended questions: Are you satisfied with the content of educational programs in math? Do we need common international requirements for quality of mathematical knowledge of engineers? Three possible answers were provided to these questions: 1) Yes; 2) No; 3) I do not know. The closed-ended question "What didactic features of mathematical knowledge formation do you prefer?" included the following answers: 1) academic; 2) applied; 3) difficult to answer. One open-ended question was proposed to professors: "How to improve the students' interest in math?" Students' questionnaire included the following closedended questions: Are you interested in mathematics? Do we need mathematical knowledge for successful professional growth? Does modern society need the mathematization of knowledge? Three possible answers were provided to these questions: 1) Yes; 2) No; 3) I do not know. One open-ended question was proposed to the students: "How do you understand the role of mathematical modeling in the optimization of modern production?" The survey results were discussed in the 11 focus groups of professors and students, each of which consisted of nine persons. In focus groups, participants were invited (personally not familiar with each other). Tasks for the formation of mathematical knowledge were developed. Levels of mathematical knowledge formation were detected. 


\section{Results}

System integrity of purpose, content, forms, methods and means of formation of fundamental mathematical knowledge depends on the need to establish relationships of mathematical concepts and theorems with methods of professional activity. The latter provides the formation of opinion about mathematical knowledge as an activity, which appears in professional problems solving. One of the axioms of mathematics education is that the main components of which are the mathematical organization of empirical material, logical organization of mathematical material and the use of the mathematical theory. Efficiency of mathematical knowledge formation is increased under the condition of learning mathematics in the process of problems solving in engineering and technological support of production. In practice, this involves mathematical creativity, including proof, supposition, and enlightenment. It follows that one must learn not only to "prove", but also "guess". Therefore, during the formation of mathematical knowledge the following is provided: a harmonic and functional analysis of specific design and technological systems, identification of common parameters and the development of mathematical models of processes and production facilities. This makes it possible to distinguish three components in the structure of mathematical activity:

- A mathematical description of the specific design and technological systems or activities on empirical material mathematization

- Identification of common parameters of design and technological systems or activity for organization of mathematical material and construction of the theory

- Mathematical modeling of processes and production facilities or activity for the implementation of developed theory.

Scientific substantiation of system integrity of purpose, content, methods, forms, means of education manifests itself in the fact that any change in one component entails a change in the other, and the whole system. Mathematics does not tolerate randomness. When designing the system integrity of purpose, content, forms, methods and means of formation of mathematical knowledge the following should be taken into account. This open, purposeful, dynamic system responds to any changes in the internal and external environment and adequately reflects these changes in the educational process. Engineering students need mathematical knowledge, especially when it comes to mathematical modeling of industry processes.

In modern conditions of computerization, the development of high-performance software tools of mathematical analysis and modeling rises. However, to assess the reliability of computer solutions, engineers need basic knowledge of mathematics. The engineer should know analytical geometry and linear algebra; sequences and series; differential and integral calculus; harmonic analysis; differential equations. Along with numerical methods; complex function; functional analysis of elements; probability theory and mathematical statistics. For technical students, mathematics is not the area of professional activities, but a means of practical problems solving. Therefore, in practical classes, students must learn to explore mathematical models "manually" and on laboratory work - with usage of modern program tools. Applied feature of mathematical 
knowledge formation means that mathematical knowledge should be formed taking into account acquisition of cultural and professional competences. According to the Russian educational standards, undergraduate-engineers must form culture of thinking, be able to logical construction of speech, teamwork, and empowerment. In practice, tasks for common cultural and professional competences acquisition (during the process of mathematical knowledge formation) are manifested in the following:

- Target (the formation of general cultural skills)

- The content (knowledge, skills, experience of their use in the process of professional problems solving, attitude toward the study of the subject)

- Forms (practice, independent work)

- Methods (group work; individual tasks; conferences; meetings/workshops with experts)

- Tools (software, models, research and academic books, etc.).

On the one hand, each of the functions of education has its task, creates a set of common cultural and professional competences, as well as the ability to self-realization. On the other hand, the functions are dialectically interrelated and complement each other. This allows saying about non-additive of functions. It was found that the formulation and implementation of tasks for common cultural and professional competences acquiring involve the interaction of teaching and learning. That is to say, professor should organize the learning process and students should actively learn and engage in research work. In turn, the partnership of the professor and students allows saying about the integration of teaching and developing educational functions. The integration of education functions in mathematical knowledge formation allows saying that mathematics concepts development is a component of human culture. Mathematization of human knowledge takes into account modern society needs. Mathematical modeling plays its role in the optimization of modern production. Therefore, in the process of mathematical knowledge formation the following abilities are created:

- Understanding the nature and significance of mathematical information in the development of modern society

- Analysis of evidence, its generalization, refutation or setting goals, finding, and constructing of proofs

- Reasoned construction of findings.

It was found that the applied feature of mathematical knowledge formation contributes to the creation of mathematical philosophy among undergraduate-engineers. Mathematical outlook can be regarded as a component of professional ideology, which includes a set of mathematical knowledge, influencing modern production technologies convergence, efficiency of problems solving and formation of readiness for further education. It was found that mathematical knowledge formation is enhanced by the mathematical component development in the professional outlook. Experimental work on the verification of didactic features effectiveness of mathematical knowledge formation took place in three phases (stating, forming, controlling). On stating step with the help 
of a questionnaire, the attitude was found of 50 professors and 300 students to the formation of mathematical knowledge. The open-ended and closed-ended questions were included. Professors' opinions are as following:

- $94 \%$ of professors think that globalization of the economy initiates the creation of common requirements for the quality of mathematical knowledge of engineers

- $86 \%$ - successive connection of mathematics with professional disciplines must be installed

- $81 \%$ - both standard and professionally oriented tasks should be solved in the math classroom

- $74 \%$ - it is necessary to include in the content of student research work some mathematical analysis of the efficiency of operating facilities, mathematical modeling

- $59 \%$ - mathematical knowledge forming is based on applied feature

- $41 \%$ - mathematical knowledge forming is based on the academic didactic features.

Student survey has shown the following:

- $39 \%$ understand the role of mathematical modeling in the optimization of modern production

- $38 \%$ - steady focus on mathematical knowledge as a condition for successful professional growth

- $15 \%$ aware of the need of modern society in the mathematization of knowledge

- Interest in mathematical science is shown in $12 \%$.

The survey results were discussed in the 11 focus groups of professors and students, each of which consisted of 9 persons. The participants of the focus groups identified the criteria for mastering mathematical knowledge: stability, autonomy and reliability. Indicators of stability criteria constitute the mathematical knowledge, skills that have been mastered by student at the stage of preparation for higher engineering education. There is no significant dynamics in the process of mathematical knowledge formation. The choice of this criterion is due to unstable interest of students in mathematics. Indicators of autonomy criteria constitute the knowledge, skills, competencies defined by the state educational standards. The choice of this criterion is due to the successful training of students and independence (autonomy) of learned mathematical knowledge, skills and competencies from the means and methods of engineering and design software production. Students possess mathematical knowledge, but do not focus on efficient and creative use of them in a real professional activity. Reliability indicators constitute the knowledge, skills, competencies, defined by relevant state educational standards, as well as the willingness to formulate objects and the production process mathematically, to use modern mathematical methods in production technology, interpret, use and evaluate mathematical results.

On the forming stage, tasks for the formation of mathematical knowledge are composed. As part of the academic features of mathematical knowledge formation, the following is proposed. 
- Tasks with not formulated questions for the development of mathematical reasoning skills, to generalize mathematical data, to reflect the interrelationship of concepts and judgments

- Tasks with missing or superfluous data to form search skills of missing components for a successful solution, to establish mathematical relationships and monitor them during the decision

- Tasks with changing content for the development of mathematical memory, ability to heuristic reasoning

- Decomposition of tass into the systems of interrelated tasks, with further using of system analysis methods for engineering solutions formalization, using standard software.

As part of the applied features of mathematical knowledge formation, the following is proposed:

- Tasks with the description of processes and products for the formation of graphic expression skills, which provides a direct indicators' measurement assessment, creation of mathematical models of processes and technical devices.

- Tasks with numerical characteristics of small sample sizes for statistical matching of constructive details sizes, statistical processing of long-term tests results for static strength of structural materials, arrangements for statistical quality control of products in its manufacturing process, evaluation of quality of diverse products, indices of product reliability.

At this stage, the students were divided into two groups. In the first group, the formation of mathematical knowledge was based on academic features, in the second - the applied features. In the control stage, levels of formation of mathematical knowledge were detected. The students were asked to answer questions and perform tasks that were evaluated by 5 -point system. The results are shown in Table 1.

Table 1. The development of mathematical knowledge of students based on academic and applied characteristics (GPA)

\begin{tabular}{|l|c|c|}
\hline \multicolumn{1}{|c|}{ Criteria and indicators } & \multicolumn{2}{c|}{$\begin{array}{c}\text { Features of mathematical } \\
\text { knowledge formation }\end{array}$} \\
\cline { 2 - 3 } & Academic & Applied \\
\hline Criterion of stability (S) & & \\
\hline 1. Knowing analytical geometry and linear algebra, differential equations & 4.8 & 4.6 \\
\hline 2. Ability to perform differential and integral calculus & 4.9 & 4.8 \\
\hline 3. Using numerical methods for solving differential and algebraic equations & 4.6 & 4.5 \\
\hline Criterion of autonomy (A) & & \\
\hline 1. Knowing elements functional analysis, differential and integral calculus & 4.8 & 4.7 \\
\hline $\begin{array}{l}\text { 2. Ability to use analytical and numerical methods for solving problems in } \\
\text { professional activity by means of standard software }\end{array}$ & 4.5 & 4.6 \\
\hline $\begin{array}{l}\text { 3. Using methods of mathematical analysis in professional activities, using } \\
\text { standard software }\end{array}$ & 4.5 & 4.8 \\
\hline Reliability criterion (R) & & \\
\hline 1. Knowing theory of probability and mathematical statistics & 4.9 & 4.8 \\
\hline
\end{tabular}




\begin{tabular}{|l|c|c|}
\hline $\begin{array}{l}\text { 2. Ability to apply probabilistic and statistical approach in solving the tech- } \\
\text { nical problems }\end{array}$ & 4.7 & 4.9 \\
\hline $\begin{array}{l}\text { 3. Using methods of mathematical modeling of processes and production fa- } \\
\text { cilities }\end{array}$ & 4.6 & 4.8 \\
\hline
\end{tabular}

Table 1 shows that in educational practice, didactic features of mathematical knowledge formation have a right to exist. Didactic features are aimed at the application of mathematical methods in production technology, striving to comprehend the truth, the development of the ability to perceive the beauty of intellectual achievement, the awareness of mathematics effectiveness. Criteria (reliability, autonomy, stability) allow identifying and characterizing reliable, self-contained, static levels of mathematical knowledge formation. For detecting levels of mathematical knowledge formation, the value $(W)$ is determined, as the sum for each criterion values: $W=K_{s}+K_{a}+K_{r}$.

Values for each criterion were calculated using the formula: $\mathrm{V}=\Sigma \mathrm{q} i / \mathrm{n}$, where qi average score obtained for index, $\mathrm{n}$ - number of criterion indicators. Values (W) from 0 to 5 , are considered conventionally as a stability level. The values of 6 to 10 - autonomous level. The values of 11 to 15 - reliable level (see Figure 1).

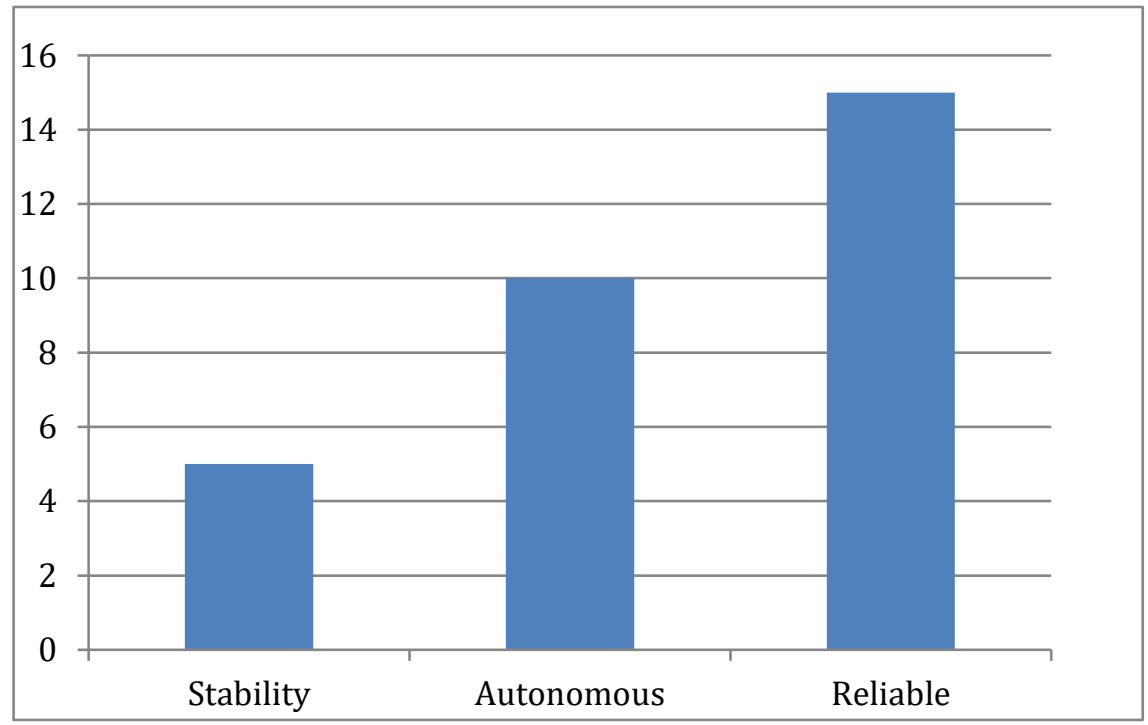

Fig. 1. Levels of formation of mathematical knowledge

Figure 1 shows that the formation of mathematical knowledge provides the transition from the stability to the level of reliability. Levels characteristics are as follows. Stability level - students possess basic mathematical knowledge, but do not realize their importance in the development of modern industries and, consequently, are not able to apply mathematical methods in solving professional problems. Autonomous level - students possess mathematical knowledge, but are not ready to independently develop mathematical models of processes and production facilities; may apply mathematical methods only using standard software. Reliable level - students are able to develop 
mathematical models of processes and industry facilities; able to apply probabilistic and statistical approach, mathematical methods for solving technological tasks. Students are as well ready to formalize the objects and processes of production, to apply modern mathematical methods in production technology, interpret, use and evaluate the mathematical results.

\section{Discussion}

The study of literature indicates the presence of a theoretical framework for the discussing problem. There are several major research trends in mathematics education. Firstly, it is a special study of content and technology of mathematical education of future engineers [10]. The International Mathematical Union has made the largest contribution to these studies. It is a global non-profit and non-governmental organization created for the development of mathematics and collaboration of scientists of all countries in the field of mathematics [11]. The International Commission on Mathematical Instruction conducts special studies of content and technology of mathematical education of future engineers [12]. The main idea of this research is to teach students to use mathematical modeling, to acquire independently further knowledge if they need them, as well as the ability to use knowledge in solving real-world problems. It is necessary to use mathematical knowledge without even noticing it. The latter can only be achieved at a sufficiently high stage of mathematical development [13]. Mathematical knowledge appeared and developed according to the needs of Natural science (Physics and Mechanics, Astronomy) and technology. The qualitative difference between mathematical knowledge is that it was initially aimed at servicing a variety of fields of science and practice, and it is a special section in the total sum of human knowledge. Mathematical knowledge was intended to systematize the facts and establish relationships. Mathematical knowledge carries a backbone role in education: develops logical thinking; provides transagreement of scientific terms, forms the ability to construct mathematical models, and assessment methods of the implementation of such models in the management of processes and objects. Secondly, the trend is related to the justification of the role of mathematical knowledge in professional problems solving [14]. The International Council for Industrial and Applied Mathematics as a worldwide organization of professional societies of applied mathematics works to promote the applications of mathematics in all parts of the world [15]. The main idea of this research trend is to form specialized skills in students for solving professional problems. Research in the framework of this trend can justify the position that mathematical knowledge is a good, for which a future specialist has a right and demand on the labor market. Mathematics is not an engineering discipline; it should not pose any technical questions but give to future engineers the necessary mathematical knowledge. Fluency in mathematical knowledge leads to a more efficient solution of professional problems. The implementation of this idea in modern practice of formation of mathematical knowledge requires system integrity purpose, content, forms, methods and means of the process. The skills are needed of application of numerical methods for solving differential and algebraic equations, methods of analytic geometry, probability theory and 
mathematical statistics in solving technical problems in development and operation of modern technology.

The third trend can be identified in the field of research of mathematical upbringing. The authors of the study believe that the possession of mathematical knowledge is a required element of a common culture, scientific basis of vision and development of intellectual abilities [16]. Mathematics, although is a purely human creation, has opened access to some of the mysteries of nature, allowed achieving success surpassing all expectations [17]. The task of mathematics does not consist in teaching calculus, but the methods of human thought in the calculation. Math classes promote moral education and develop virtues. Mathematical knowledge is based on the principle of evidence, and this is one of the most important moral principles, i.e. one cannot judge without evidence. To give some calculus in accordance with the current level of mathematical rigor it is necessary to present complex evidence. However, engineers need calculus for its practical application. They have neither the time nor the training, nor the interest to include loads of evidence and to assess all the subtleties. As a result, there is a strong temptation to omit all the evidence. However, in doing so, one reduces to the primitive level of calculus [18].

The subject of many studies was the formation of mathematical thinking [19], [20]. The authors of the study believe that the feature of mathematical thinking - originality - a valuable ability in the modern world. According to these authors, mathematical thinking is the purpose of studying mathematics, and the condition for the development of mathematical knowledge [21]. In the essay, "The Assayer" Galileo says "philosophy [nature] is written in that great book whichever is before our eyes - I mean the universe - but we cannot understand it if we do not first learn the language and grasp the symbols in which it is written".

The fourth trend can be identified by the study of professors' mathematical literacy as the ability to formulate, use and interpret mathematics in a variety of contexts [22]. Professor of mathematics has an excellent opportunity. If he/she fills the allotted training time by coaching students in standard exercises, he/she will kill their interest, hamper their cognitive development and miss opportunities. However, such professor might arouse the curiosity in students, offer them the tasks that fit with their knowledge. Professor's leading questions will help them meet challenges. Professor will be able to instill in them a taste for independent thinking and to develop the necessary capacity [18]. The task of the professor is to select the teaching material and to present it in such way that together with upbringing of "mathematical view" to facilitate as far as possible the further application of mathematics to special disciplines. In solving any problem, there is a grain of discovery. If the problem is solved by own means, the person may experience voltage of mind that leads to discovery and enjoy victory. Such emotions experienced in the impressionable age, may awaken a taste for mental work and leave its imprint on mind and character. The student may find that mathematical problem is sometimes just as exciting as the crossword, and intense mental work can be just as desirable exercise as swift tennis. The pleasure of math lessons one cannot forget and then the math will take a certain place in one's life: as the subject of amateur hobby or as a tool in the professional work or as a way for personal glory [18]. Research in the 
framework of this trend can justify the provisions of the subjective role of the professor in the process of formation of mathematical knowledge.

Fifth tendency constitute works on methodology research of mathematical education [1]. In March 2019, there was published the first article based on 50 years of archive Journal for Research in Mathematics Education (JRME). The authors note that in the studies of mathematics education, questions about the availability of mathematical knowledge, their practical orientation, scientific substantiation of the results are important [23]. The peculiarity of mathematical knowledge is that it is presented in a logical structure, it reflects the quantitative relations and spatial forms of the world, conclusively, abstracted from the qualitative features of objects and processes. At the same time, mathematical knowledge, as well as any knowledge, is a sensible truth, subjective image of the objective world. Math builds up at the boundary of several contending with each other visions of number, multiplicity, infinity. This leads to a struggle of different logics and heuristics [17]. The conclusions drawn by the listed authors served as the basis of our study. However, despite the great interest in mathematical education, the level of mathematical knowledge of students is poor. The subject of most of the studies - mathematics education of school pupils or mathematical modeling in engineering. There is not enough attention for students' mathematical knowledge formation at the undergraduate level. The current stage of mathematical knowledge formation of future engineers is characterized by changes in educational values, the output of mathematics beyond its logical form and focus on the development of mathematical and philosophical potential of the person.

\section{Conclusion}

In today's post-industrial society, when the development of machine-building production is depending on technical possibilities and socio-political, cultural relations, the mathematical knowledge formation in the future engineer is focused on mastering of knowledge about the dependence of object properties from its structure and structure from properties. Mathematical knowledge allows a future engineer to possess the following.

- A system of universal scientific knowledge and skills

- Responsibility to science and humanity

- Analysis of the consequences of engineering choice

- The ability to adapt quickly to the flow of information and technology transfer from different scientific areas

- Readiness for various types of professional activity and the creation of competitive products, the development of convergent technologies and continuing education throughout life

- Mathematical component in the professional outlook.

In terms of mathematical modeling and analysis by high performance software tools engineer needs fundamental mathematical knowledge to assess the reliability of computer solutions. Didactic features of mathematical knowledge formation (academic and 
applied) comprise interaction of teaching and learning, include organization by professor of learning process, students' active learning and research work. These results allow outlining the prospects for further research of the problems associated with the pedagogical conditions of mathematical knowledge formation: development of professors' ability for pedagogical management of mathematical knowledge formation process. Along with development of mathematical thinking of students and establishing successive relationships of mathematics with professional disciplines. Article materials may be useful for professors of mathematical disciplines in universities.

\section{References}

[1] M. Doorman, "Design and research for developing local instruction theories", Avances de Investigación en Educación Matemática, no. 15, pp. 29-42, 2019. https://doi.org/10.35763/ aiem.v0i15.266

[2] L.D. Guzmán, and \& J. Craig, "The World in Your Pocket: Digital Media as Invitations for Transdisciplinary Inquiry in Mathematics Classrooms", Occasional Paper Series, vol. 2019, no. 41 , p. 6, 2019.

[3] UNESCO on the World Conference on Higher Education. Higher Education in the TwentyFirst Century: Vision and Action., 1998. [Online]. Available:[http://unesdoc. unesco.org/images/0011/001163/116345E.pdf (Accessed: Jan. 09, 2019].

[4] State Program of the Russian Federation Development of Education for 2013-2020. [Onlina]. Available: https://zakonbase.ru/content/part/1218628 [Accessed: March 30, 2019].

[5] Program 973. [Online]. Available: http://wiki.china.org.cn/wiki/index.php/973 Program [Accessed: Apr 09, 2019].

[6] ARISE 2: Advancing Research in Science and Engineering, 2017. [Online]. Available: https://www.amacad.org/multimedia/pdfs/publications/researchpapersmonographs/arise2. pdf [Accessed: Jan. 09, 2019].

[7] Concepts of development of mathematics education in the Russian Federation: Government Decree of December 24, 2013 No. 2506. [Online]. Available: http://minobrnauki. rf/documents/3894 [Accessed: Apr 14, 2019].

[8] A.A. Muravyeva, O.N. Oleynikova, N.M. Aksenova, and E.M. Dorozhkin, "National Qualifications System in Russia - an Epistemological Perspective", The Education and science journal, vol. 21, no. 4, pp. 92-114, 2019. https://doi.org/10.17853/1994-5639-2019-4-92$\underline{114}$

[9] I.V. Malanichev, and F. G. Akhmadiev, "Simulation of Non-Newtonian Emulsion Flows in Microchannels", Journal of Engineering Physics and Thermophysics, vol. 88, no. 6, pp. 1483-1490, 2015. https://doi.org/10.1007/s10891-015-1334-Z

[10] P. Drijvers, "Head in the clouds, feet on the ground-A realistic view on using digital tools in mathematics education", Vielfältige Zugänge zum Mathematikunterricht, Springer Spektrum, Wiesbaden, 2019, pp. 163-176. https://doi.org/10.1007/978-3-658-24292-3_12

[11] IMU, International Mathematical Union. [Online]. Available: https://www.mathunion.org/ [Accessed: Apr 14, 2019].

[12] ICMI Studies. [Online]. Available: https://www.mathunion.org/icmi/digital-library/icmistudies [Accessed: Apr 14, 2019].

[13] S. La Bastide-van Gemert, All Positive Action Starts with Criticism: Hans Freudenthal and the Didactics of Mathematics, Springer, 2015. https://doi.org/10.1007/978-94-017-93346_4 
[14] S. Sazonov, E. Kharlamova, I. Chekhovskaya, and E. Polyanskaya, "Mechanism of determination of effectiveness of spending assets of endowment funds on the basis of mathematical models", International Journal of Educational Management, vol. 31, no. 1, pp. 21-29, 2017. https://doi.org/10.1108/ijem-02-2016-0040

[15] ICIAM, The International Council for Industrial and Applied Mathematics. [Online]. Available: http://www.iciam.org/ [Accessed: Apr 14, 2019].

[16] M. Goos, and A. Bennison, "A zone theory approach to analysing identity formation in mathematics education", ZDM, vol. 51, no. 3, pp. 405-418, 2019. https://doi.org/10.1007/ $\underline{\mathrm{s} 11858-018-1011-8}$

[17] M. Kline, Mathematics, the loss of certainty. SERBIULA (sistema Librum 2.0), 2019. [Online]. Available: https://www.researchgate.net/publication/44362037 Mathematics_the_loss_of_certainty_Morris_Kline [Accessed: Apr 06, 2019].

[18] G. Polya, How to solve it: A new aspect of mathematical method (No. 246), Princeton university press, 2004.

[19] D. Cēdere, I. Jurgena, and V. Targamadze, "Interest of Latvian and Lithuanian students in science and mathematics", Journal of Baltic Science Education, vol. 17, no. 1, pp. 31-42, 2018.

[20] L. McDonnell, and D. O'Neil, "Developing tomorrow's engineers: a case study in instrument engineering", Education + Training, vol. 51, no. 3, pp. 210-214, 2009. https://doi. org/10.1108/00400910910960740

[21] H. Bass, and D. L. Ball, "Review of Does Mathematical Study Develop Logical Thinking? Testing the Theory of Formal Discipline", International Journal of Research in Undergraduate Mathematics Education, vol. 4, no. 3, pp. 442-447, 2018. https://doi.org/10. 1007/s40753-018-0076-7

[22] B. Y1ldırım, and S. Sidekli, "Stem applications in mathematics education: The effect of stem applications on different dependent variables", Journal of Baltic Science Education, vol. 17, no. 2, pp. 200-2014, 2018.

[23] J. Cai, A. Morris, C. Hohensee, S. Hwang, V. Robison, M. Cirillo, ... and J. Hiebert, "Posing significant research questions", Journal for Research in Mathematics Education, vol. 50, no. 2, pp. 114-120, 2019. https://doi.org/10.5951/jresematheduc.50.2.0114

\section{$7 \quad$ Authors}

Natalya Pugacheva PhD, Professor, Department of Building Technology, Kazan State University of Architecture and Engineering, Kazan, Russia. natalya-pugacheva@yandex.ru

Tatyana Kirillova PhD, Professor, Center of a research of problems of execution of criminal penalties and psychological ensuring professional activity of staff of penal correction system, Research Institute of the Federal Penitentiary Service of Russia, Moscow, Russia.

Olga Kirillova PhD, Professor, Department of philosophy, sociology and pedagogy, Chuvash State University named after Ulyanov, Cheboksary, Russia.

Aleksandr Lunev PhD, Professor, Department of Engineering Production Technology, Kazan National Research Technical University named after A.N. Tupolev-KAI, Kazan, Russia.

Oksana Pavlova - PhD, Associate Professor, Department of Pedagogy and Acmeology personalities, Kostroma State University, Kostroma, Russia.

Article submitted 2019-09-16. Resubmitted 2019-10-17. Final acceptance 2019-10-18. Final version published as submitted by the authors. 